\title{
Advancements in fast epitaxial high temperature brazing of single crystalline nickel based superalloys
}

\author{
B. Laux, S. Piegert, J. Rösler \\ Technische Universität Braunschweig, Institut für Werkstoffe, 38106 Braunschweig, Germany, Tel.: \\ +49-531-3913069, FAX: +49-531-3913058, E-Mail: b.laux@tu-bs.de
}

Keywords: repair of nickel based superalloys, diffusion brazing, epitaxial solidification

\begin{abstract}
New advanced braze alloys for the fast epitaxial repair of cracks in components made of single crystalline nickel based superalloys have been developed. Recent experiments with nickel-manganese based systems have demonstrated that these alloys provide a fast epitaxial solidification even of wide gaps in the range of $300 \mu \mathrm{m}$, due to the high solubility of manganese in nickel. Furthermore, silicon was found as a suitable additional melting point depressing element which allows to restrict the amount of manganese. Now these braze alloys have been enhanced in order to obtain better high temperature stability as well as appropriate corrosion behavior. The melting behavior of the new braze alloys was simulated by ThermoCalc, whereby special focus was on a high $\gamma^{\prime}$ solvus temperature combined with a beneficial melting behavior. The enhanced alloy Ni-25Mn-5Cr-3Al-3Ti was found to be suitable for fast epitaxial solidification. Several brazing experiments were carried out. Since a microstructure similar to that of the base material is aspired, subsequent to the brazing cycle different heat treatments were applied. A heat treatment consisting of a solution annealing followed by a precipitation hardening, produced a microstructure which was very similar to that within the base material.
\end{abstract}

\section{Introduction}

Nowadays, turbine components in aircraft engines as well as in stationary gas turbines are frequently made of nickel based superalloys, since these materials provide a good high temperature durability [1-6]. However, due to the high costs of superalloy components repair of damaged components instead of complete exchange is of special economical interest. The most common damages are cracks. However, weldability of cracks in components from nickel based superalloys is limited since the coef- ficients of thermal expansion of the $\gamma$ and $\gamma^{\prime}$ phase are very different resulting in internal stresses [7]. Therefore, the most common technology of filling cracks is the repair by high temperature diffusion brazing $[3,4,6,7]$. This repair technology is characterized by the use of a braze alloy, similar to the base material, which is enhanced by a fast diffusing melting point depressant like boron and/or silicon inducing solidification by diffusion into the base material [3, 7-11]. Due to the high stresses in turbine components, the primary purpose of healing is to produce a single crystalline microstructure within the brazed gap which means that an epitaxial solidification is achieved.

Epitaxial solidification of braze joints has been demonstrated within several publications. The most serious problem of the current technologies are the very long hold times that are necessary, since the solidification is diffusion controlled [4, 12-16]. However, silicon and boron have a very low solubility in the nickel matrix, hence, a complete diffusion out of the braze gap is essential for isothermal solidification. If the particular solubility is exceeded during solidification, brittle borides and silicides precipitate which lead to nucleation sites for equiaxed grains. The solidification then terminates with an eutectic reaction, resulting in a polycrystalline microstructure with brittle phases in the center of the braze gap.

In [16] an ideal brazing temperature was found which is a compromise between high diffusivity at increased temperatures and remelting of the substrate surface which is less pronounced at lower temperatures. A coherence between hold time at the ideal temperature $(1423 \mathrm{~K})$ and epitaxial solidified gap width was deduced from several brazing experiments with boron containing braze alloys. Based on the results of [16], for $300 \mu \mathrm{m}$ wide gaps a hold time of about $50 \mathrm{~h}$ can be predicted.

In contrast, nickel-manganese based braze alloys developed within recent work, allow a complete epitaxial solidification of gaps of the same width within 10 min which is 300 times faster (Fig. 1 (a)) [17]. The advantage of these 


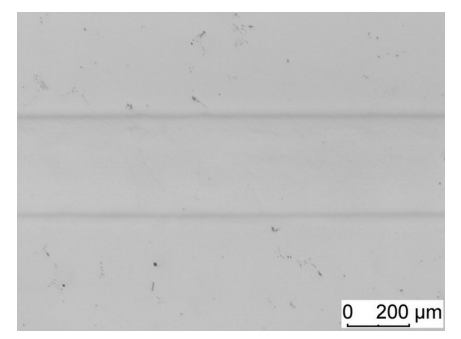

Figure 1: Ternary system Ni-25Mn-2Si: Light microscope image of the brazed gap $(300 \mu \mathrm{m})$, prepared with V2A etchant [17]

new systems is the complete miscibility down to relatively low temperatures. Therefore, solidification is not diffusion controlled but temperature driven. Since manganese as melting point depressant is not as effective as boron or silicon, high amounts of manganese are necessary to provide a suitable melting interval. To limit the fraction of manganese, small amounts of silicon were added as second melting point depressant, whereby detraction of the epitaxial solidification could be observed. All brazed samples were examined by means of light and scanning electron microscopy, particularly EBSD analysis (Fig. 2). Misorientation measurements confirmed complete epitaxial solidification, a misorientation of $8^{\circ}$ has not been exceeded. Altogether, one binary and two ternary alloys such as Ni-36.7Mn, Ni-20Mn-2Si and Ni-25Mn-2Si (fractions in wt.-\%), were found to be suitable for wide gap brazing of single crystalline nickel based superalloys.

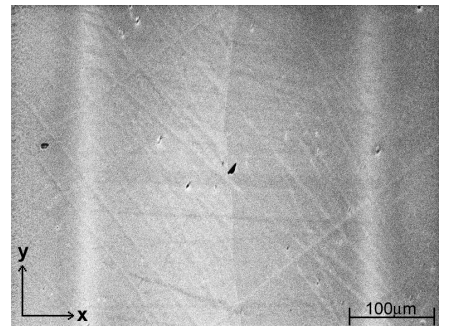

(a) SEM image: Parallel gap, $300 \mu \mathrm{m}$

Figure 2: Ni-20Mn-2Si, EBSD analysis: SEM image with corresponding $\langle 001\rangle$ pole figure

With regard to an appropriate high temperature stability as well as a sufficient oxidation and corrosion behavior, aluminium and chromium are very important elements acting as $\gamma$ solid solution hardeners, oxide film formers $\left(\mathrm{Al}_{2} \mathrm{O}_{3}, \mathrm{Cr}_{2} \mathrm{O}_{3}\right)$ and $\gamma^{\prime}$ formers (Al) [18]. Thus, the binary and ternary nickel-manganese based systems were enhanced by these two elements. Furthermore, titanium was found as suitable substitutional element for $\mathrm{Si}$. Thermodynamic simulations were carried out to find compositions with a beneficial melting behavior, i. e., a liquidus temperature in the range of $1273 \mathrm{~K}$ as well as a solidius temperature of about $1473 \mathrm{~K}$. Several heat treatments were conducted in order to produce a microstructure with a $\gamma / \gamma^{\prime}$ morphology which is similar to that within the base material. Additionally, microhardness measurements were carried out within the gaps brazed with the enhanced system compared to those gaps brazed with the ternary system $\mathrm{Ni}-20 \mathrm{Mn}-2 \mathrm{Si}$.

\section{Thermodynamic Simulations}

In this work thermodynamic simulations were conducted by means of ThermoCalc, Version TCR and the database TTNi7, particularly developed for nickel based superalloys. Quasi binary phase diagrams based on the ternary Ni-25Mn-2Si were calculated (Fig. 3): Firstly $\mathrm{Cr}$ and $\mathrm{Al}$ were added, afterwards, Si was replaced by Ti. The plotted phase boundaries mark the appearance and disappearance of the phases which form with decreasing temperatures. For example: The liquidus line is labeled by the precipitation of the $\gamma$ phase (in case of high amounts of Al, the first solid phase is NiAl, Fig. 3 (a)). The solidus line is marked by the disappearance of the liquid phase (L). Following the simulations, in all silicon containing systems the G-Phase precipitated during cooling. This phase could also be observed within the ternary Ni-Mn$\mathrm{Si}$ systems and was identified as a cubic intermetallic $\mathrm{Ni}_{16} \mathrm{Si}_{7} \mathrm{Mn}_{6}[17,19]$. However, this phase could not be detected by means of light microscopy and SEM within the brazed gaps, therefore, either the prediction of the GPhase in the simulations is not correct, or its precipitation morphology is very fine.

The quasi binary phase diagrams show that $\mathrm{Al}$ as well as $\mathrm{Cr}$ do not significantly influence the melting interval. As $\mathrm{Al}$ exceeds 4 wt.- $\%$, the formation of the $\mathrm{NiAl}$ phase whose precipitation results in lower amounts of $\gamma^{\prime}$, is predicted. Additionally, the melting interval is widened by the addition of $\mathrm{Al}$ which leads to lower solidus temperatures. Thus, the $\mathrm{Al}$ fraction was restricted to $3 \mathrm{wt} .-\%$ (Fig. 3 (a)). The addition of $\mathrm{Cr}$ to the ternary Ni-Mn-Si system causes that the $\gamma^{\prime}$ precipitation is shifted to lower temperatures (Fig. 3 (b)). Therefore, with regard to a good high temperature durability requiring high amounts of $\gamma^{\prime}$, high fractions of $\mathrm{Cr}$ are not useful. In (Fig. 3 (c)) 3 wt.- $\%$ of $\mathrm{Al}$ were fixed, whereby the amount of $\mathrm{Cr}$ was varied between 0 and $10 \mathrm{wt} . \%$. As $\mathrm{Al}$ stabilizes $\gamma^{\prime}$, the corresponding solvus line is shifted to higher tempera- 

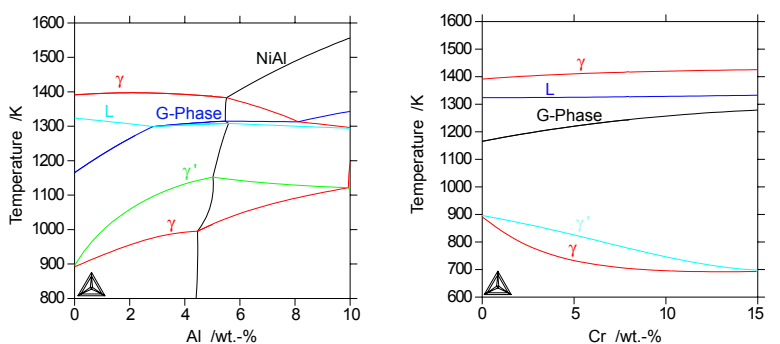

(a) Ni-25Mn-2Si: ture versus fraction of $\mathrm{Al}$

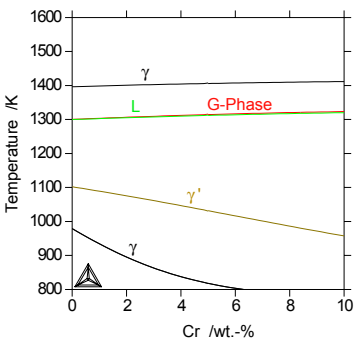

(c) Ni-25Mn-2Si-3Al: Temperature versus fraction of $\mathrm{Cr}$ (b) Ni-25Mn-2Si: Temperature versus fraction of $\mathrm{Cr}$

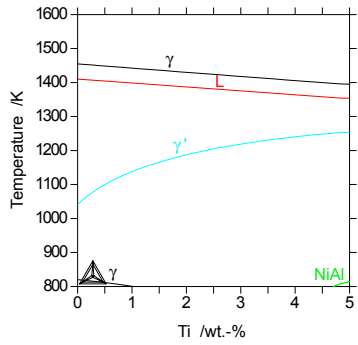

(d) Ni-25Mn-5Cr-3Al: Temperature versus fraction of $\mathrm{Ti}$

Figure 3: Quasi binary phase diagrams based on the ternary Ni-25Mn-2Si system; addition of $\mathrm{Cr}$, $\mathrm{Al}$ and replacement of Si by Ti, simulated with ThermoCalc, Version TCR

tures. In order to avoid the formation of $\mathrm{NiAl}$ and, furthermore, to obtain a high amount of $\gamma^{\prime}$, the $\mathrm{Al}$ and $\mathrm{Cr}$ fraction were fixed at 3 wt.- $\%$ and 5 wt.- $\%$, respectively. However, since $\mathrm{Al}$ as well as $\mathrm{Cr}$ stabilize the G-phase (Figs. 3 (a), (b)), the addition of both elements results in very high precipitation temperatures of the intermetallic. It is formed previous to $\gamma^{\prime}$ and thus, reduces the amount of $\gamma^{\prime}$. Therefore, as second melting point depressant $\mathrm{Ti}$ was selected instead of Si (Fig. 3 (d)), since Ti has several further advanteageous effects: The melting interval is narrowed, $\gamma^{\prime}$ is stabilized and, furthermore, the wettability is improved [17].

As result from the thermodynamic simulations the alloy Ni-25Mn-5Cr-3Al-3Ti was selected for the brazing experiments, due to its beneficial melting behavior and high $\gamma^{\prime}$ precipitation temperature. The corresponding calculated phase transformation temperatures are listed in Tab. 1. Previous to the experiments a kinetic simulation was carried out to examine the completely diffusion controlled solidification compared to complete equilibrium assumed one.

\section{Experiments}

\section{Brazing Experiments}

Brazing experiments were conducted with the help of parallel gap samples (Fig. 4) which were fabricated from a single crystalline nickel based superalloy with the following composition (in wt.- \%): Ni-7.5Co-7.0Cr-1.5Mo5.0W-6.5Ta-6.2Al-3.0Re. The samples were prepared from $1.9 \mathrm{~mm}$ thick sheets using a cutting machine with a $300 \mu \mathrm{m}$ thick blade. Since crack formation within turbine components normally occurs perpendicular to the $\langle 001\rangle$ direction of the single crystal, the cutting direction is also perpendicular to $\langle 001\rangle$.

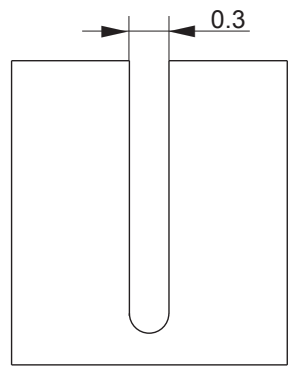

Figure 4: Geometry of the braze gap specimens: Parallel gap, $300 \mu \mathrm{m}$

For producing the selected alloy a vacuum arc furnace was used, whereby a small lens with a weight of about $10 \mathrm{~g}$ was melted. Afterwards, calorimetric analysis (Netzsch DSC 404 C Pegasus ${ }^{(C)}$ ) was conducted to measure the liquidus and solidus temperatures as well as the $\gamma^{\prime}$ precipitation temperature (Tab.1). The heating curve, which was used for evaluation, is depicted in Fig. 5. Three peaks can be observed. According to DIN 51005, as solidus and liquidus temperatures the intersection of tangents at the rising and falling slopes (peak No.3) with the extrapolated base line were read off. As $\gamma^{\prime}$ precipitation temperature the falling edge of the second peak was regarded to allow a compatibility with the thermodynamic simulations in which $\gamma^{\prime}$ is the second precipitating phase. In the calorimetric measurements this temperature is characterized by a completed phase transformation, therefore, the corresponding falling edge of the DSC curve has to be taken into account. For the first peak no corresponding phase formation was calculated by the simulations. Further research has to be undertaken to reveal the corresponding phase transformation occuring within this temperature range.

The results from the DSC measurements are listed 
in Tab. 1 in comparison to the calculated temperatures. Moreover, the deviation between calorimetric measurement and simulation is specified. It can be seen, that all calculated temperatures, particularly the $\gamma^{\prime}$ precipitation temperature, are very low. This is in agreement to simulations calculated for the binary and ternary $\mathrm{Ni}$ Mn based systems [17]. Probably, the high amount of manganese causes this relatively high deviation, since a database which was specially developed for nickel based superalloys, has been used. However, Mn as alloying element in these alloys is very unusual.

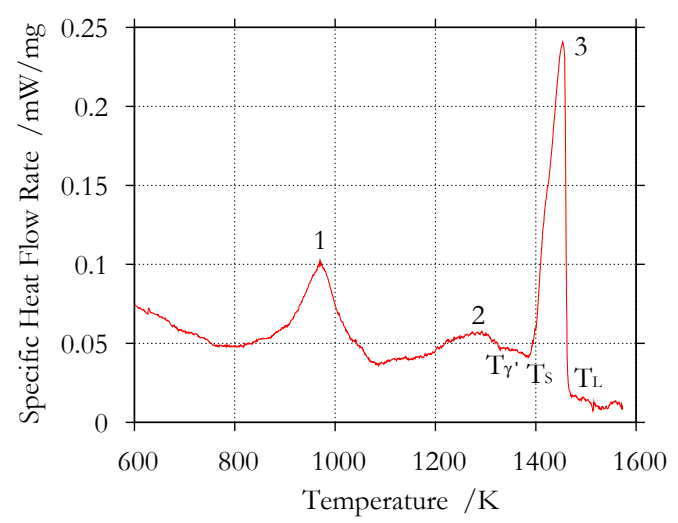

Figure 5: DSC heating curve for the selected braze alloy

Table 1: Solidus, liquidus and $\gamma^{\prime}$ precipitation temperatures as well as melting interval (in $\mathrm{K}$ ) of the selected braze alloy (Ni25Mn-5Cr-3Al-3Ti), simulated with ThermoCalc, Version TCR and measured by DSC; in the third column the deviations are listed

\begin{tabular}{lccc}
\hline & DSC & TCR & $\boldsymbol{\Delta D S C , ~ T C R}$ \\
\hline $\mathbf{T}_{\mathrm{L}}$ & 1462 & 1418 & 44 \\
$\mathbf{T}_{\mathrm{S}}$ & 1392 & 1375 & 17 \\
$\boldsymbol{\Delta} \mathbf{T}_{\mathrm{SL}}$ & 70 & 43 & 27 \\
$\mathbf{T}_{\gamma^{\prime}}$ & 1330 & 1219 & 111 \\
\hline
\end{tabular}

Subsequent to DSC measurements several brazing experiments were conducted. The melted braze alloy lens was cut into thin bars and, after cleaning, applied on the ultrasonically cleaned parallel gap samples. Afterwards, three different brazing cycles were carried out in a vacuum furnace (Fig. 6). In each cycle the first step was heating to $1273 \mathrm{~K}$ with a temperature gradient of $10 \mathrm{~K} / \mathrm{min}$. After a hold time of $10 \mathrm{~min}$ for homogenization the samples were

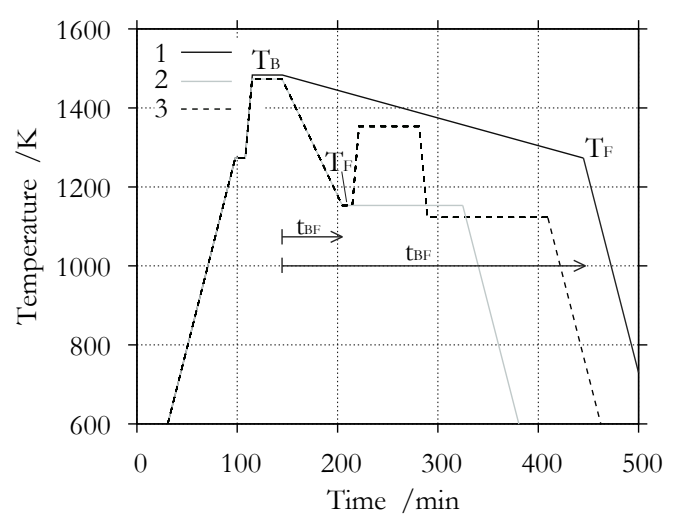

Figure 6: Different brazing cycles

Table 2: Characterizing temperatures (brazing temperature $T_{\mathrm{B}}$, final temperature $T_{\mathrm{F}}$, time $t_{\mathrm{BF}}$ between $T_{\mathrm{B}}$ and $T_{\mathrm{F}}$ and heat treatment of the three selected brazing cycles

\begin{tabular}{ccccc}
\hline & $\mathbf{T}_{\mathrm{B}} / \mathrm{K}$ & $\mathbf{T}_{\mathrm{F}} / \mathrm{K}$ & $\mathbf{t}_{\mathrm{BF}} / \mathrm{h}$ & Heat treatment \\
\hline $\mathbf{1}$ & 1483 & 1273 & 5 & - \\
$\mathbf{2}$ & 1473 & 1153 & 1 & $2 \mathrm{~h}$ at $1153 \mathrm{~K}$ \\
$\mathbf{3}$ & 1483 & 1153 & 1 & $1 \mathrm{~h}$ at $1353 \mathrm{~K}$, \\
& & & & $2 \mathrm{~h}$ at $1123 \mathrm{~K}$ \\
\hline
\end{tabular}

heated with $30 \mathrm{~K} / \mathrm{min}$ to brazing temperature $T_{\mathrm{B}}$ which was hold for $30 \mathrm{~min}$. Brazing temperature was chosen $20 \mathrm{~K}$ above the liquidus temperature (DSC: $1462 \mathrm{~K}$ ) providing complete melting to avoid nucleation sites for stray grains. The further temperatures characterizing the three brazing cycles, are listed in Tab. 2. $T_{\mathrm{B}}$ of the first cycle was $1483 \mathrm{~K}$, whereby for cycles 2 and $3 T_{\mathrm{B}}$ was reduced by $10 \mathrm{~K}$ to $1473 \mathrm{~K}$ to avoid $\gamma^{\prime}$ coarsening in the base material. The time $t_{\mathrm{BF}}$ between the brazing temperature $T_{\mathrm{B}}$ and the final temperature $T_{\mathrm{F}}$ which denotes the end of the brazing cycle, varied between $5 \mathrm{~h}$ and $1 \mathrm{~h}$. With exception of the first cycle, subsequent to the particular brazing cycle different heat treatments were applied in order to produce a $\gamma / \gamma^{\prime}$ morphology similar that of the base material: During the second cycle a precipitation hardening at $1153 \mathrm{~K}$ was conducted, within the third cycle a solution annealing was followed by a precipitation hardening. 


\section{Results}

For light microscopic analysis all brazed samples were ground and polished, afterwards two etchants were used for preparation: V2A etchant $(200 \mathrm{ml}$ distilled water, $200 \mathrm{ml}$ hydrochlorid acid (37\%), $20 \mathrm{ml}$ nitric acid (65\%), $0.6 \mathrm{ml}$ Vogel-Sparbeize (proprietary product of Buehler company)) for the visualization of grain boundaries, and molybdenum acid etchant $(100 \mathrm{ml}$ distilled water, $3 \mathrm{~g}$ molybdenum acid, $100 \mathrm{ml}$ hydrochloric acid $(37 \%), 20 \mathrm{ml}$ nitric acid $(65 \%)$ ) for the analysis of the $\gamma / \gamma^{\prime}$ microstructure. The results are depicted in Figs. 7-9. Within the
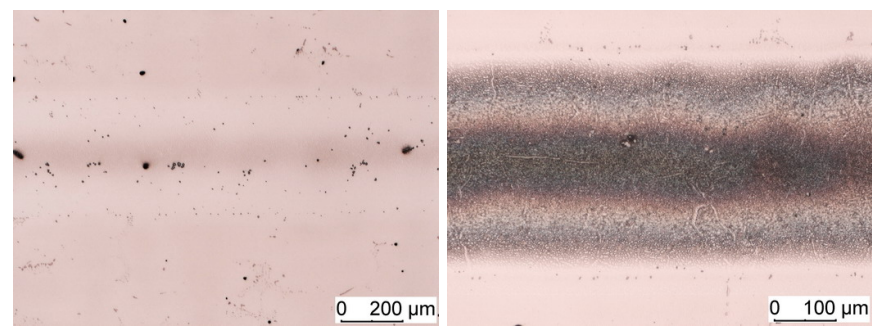

(a) Complete gap, V2A etchant (b) Complete gap, molybdenum acid etchant
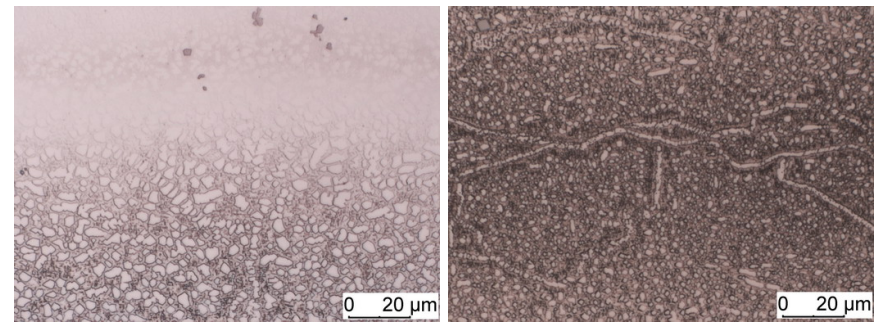

(c) Bonding zone, molybdenum acid etchant

(d) Braze gap center, molybdenum acid etchant

Figure 7: Cycle 1: Light microscope images of the brazed gaps prepared with V2A and molybdenum acid etchant

braze gaps prepared with V2A etchant, no grain boundaries are visible (Figs. 7 (a), 8 (a), 9 (a)). Therefore, it is concluded that complete epitaxial solidification was achieved using the enhanced alloy system Ni-25Mn-5Cr3Al-3Ti. However, due to the three different brazing cycles varying braze results were produced. In the second and the third brazing cycle a faster cooling was applied, hence, a dendritic growth can be observed (Figs. 8 (b), 9 (b)). In the center of the gap brazed according to cycle 2 , a second phase has precipitated, whereby a preferential direction diagonal to the $\langle 001\rangle$ direction can be observed (Figs. 8 (a), (d)).

The preparation with molybdenum acid etchant visualizes the $\gamma / \gamma^{\prime}$ microstructure. However, the etching be-

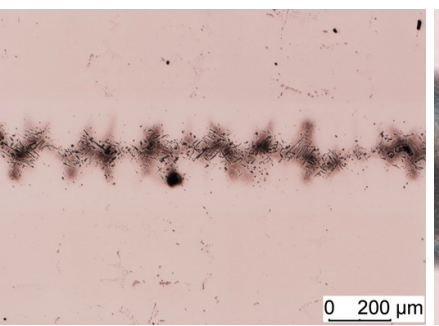

(a) Complete gap, V2A etchant

(b) Complete gap, molybdenum acid etchant

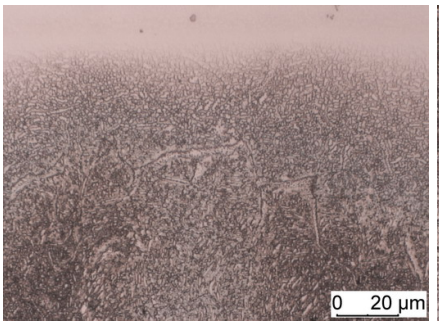

(c) Bonding zone, molybdenum acid etchant

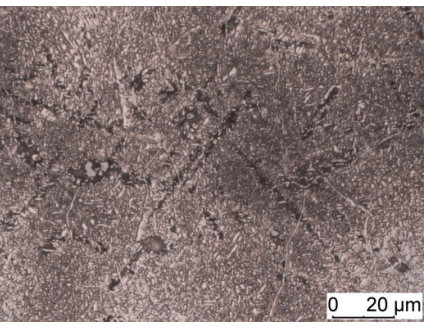

(d) Braze gap center, molybdenum acid etchant

Figure 8: Cycle 2: Light microscope images of the brazed gaps prepared with V2A and molybdenum acid etchant
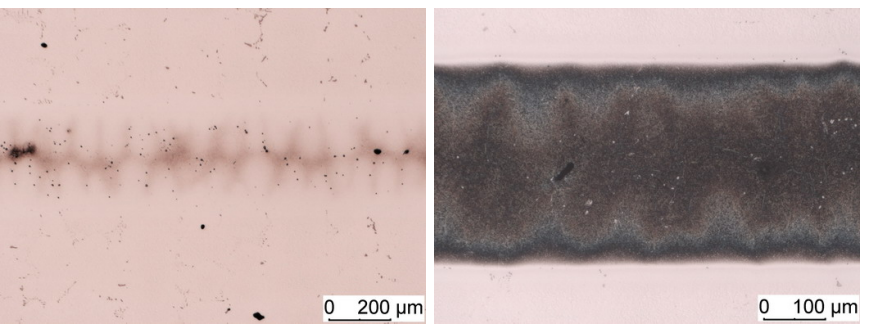

(a) Complete gap, V2A etchant

(b) Complete gap, molybdenum acid etchant
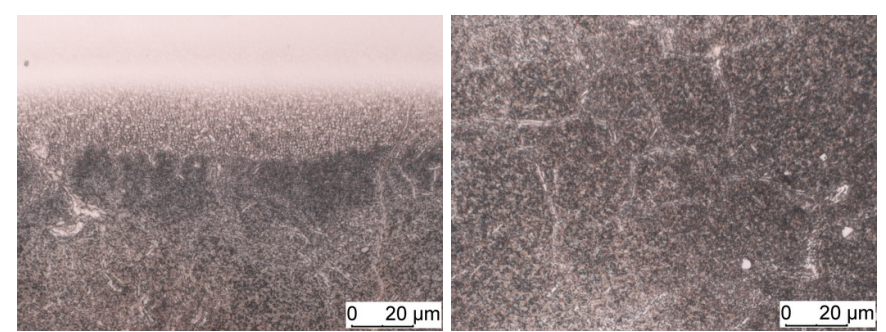

(c) Bonding zone, molybdenum (d) Braze gap center, molybdeacid etchant

num acid etchant

Figure 9: Cycle 3: Light microscope images of the brazed gaps prepared with V2A and molybdenum acid etchant

havior is different from that of commercial nickel based superalloys: Usually, the $\gamma^{\prime}$ phase is dissolved out of the 


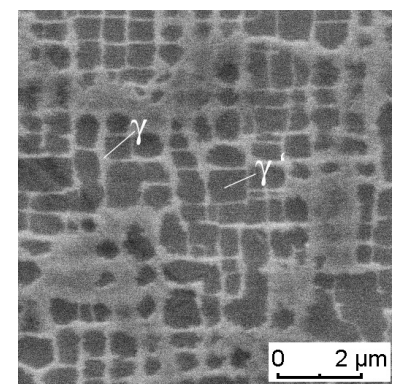

Figure 10: Base material after brazing according to cycle 3 , prepared with molybdenum acid etchant

$\gamma$ matrix, in this case, in the light microscope pictures the $\gamma^{\prime}$ precipitations appear as bright phase, the surrounding $\gamma$ matrix appears dark. Probably, the different compositions of the two phases within the braze alloy cause a different etching behavior.

Obviously, the $\gamma / \gamma^{\prime}$ microstructure produced by the first cycle is relatively coarse, however, the $\gamma^{\prime}$ precipitations become smaller in the center of the braze gap. Furthermore, within the gaps brazed according to the first cycle, long 'pearl cord like' $\gamma$ ' precipitations are visible whose quantity decrease within the gaps brazed according to the other cycles. Moreover, the microstructure is finer within those gaps.

In addition to the analysis by means of light microscopy, scanning electron microscopy (SEM) combined with energy dispersive X-ray spectroscopy (EDX) was carried out; on the one hand, in order to allow a closer look on the microstructure, on the other hand, to verify the bright precipitations as $\gamma^{\prime}$ phase (Fig. 11). The analyzed samples were also prepared with molybdenum acid etchant; in all figures the braze gap orientation is the same as in Fig. 12-14.

Within the gap brazed according to the first cycle, a bidisperse structure is visible which consists of large round and small plate-shaped precipitations within a dark appearing matrix (Fig. 11 (a), (b)). EDX ana-lysis which was examined on the large bright phases as well as on the dark areas, revealed that the bright precipitations are Al-, Ti- and Ni-rich, whereby within the dark matrix higher amounts of $\mathrm{Cr}$ and $\mathrm{Mn}$ were detected. With regard to the typical distribution coefficients of those elements within nickel based superalloys [18], it is concluded that the bright precipitations correspond to the $\gamma^{\prime}$ phase, whereby the dark areas are the $\gamma$ matrix. The exact identification of the bright plate-shaped phases has not yet been successful due to their fine precipitation morphol-

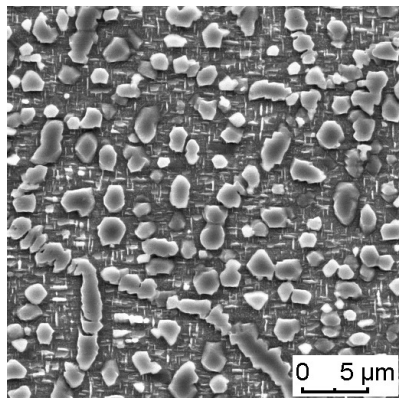

(a) Cycle 1: gap center

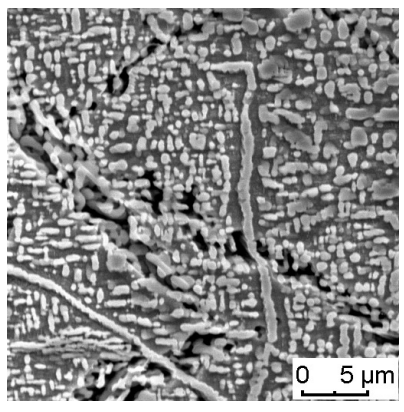

(c) Cycle 2: Gap center

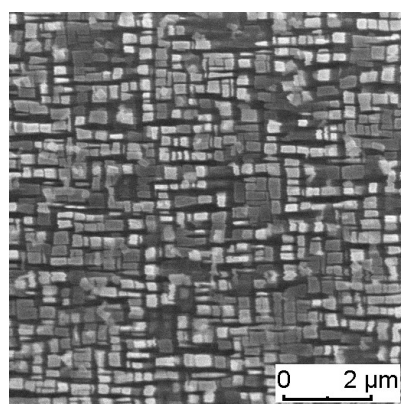

(e) Cycle 3: Gap center

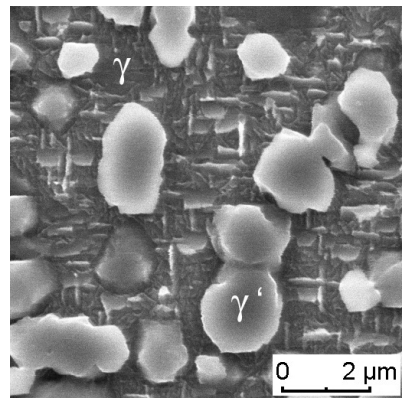

(b) Cycle 1: Gap center

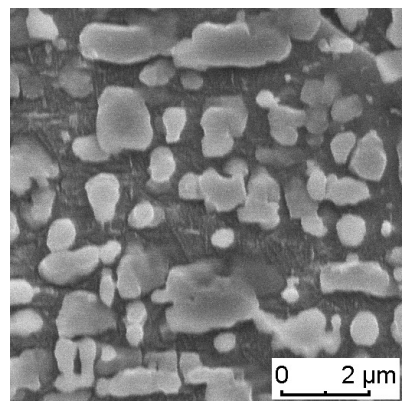

(d) Cycle 2: Gap center

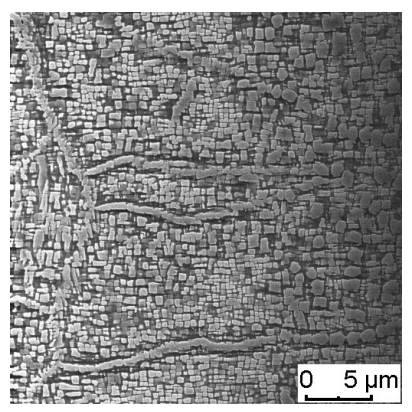

(f) Cycle 3: Gap boundary (base material right)
Figure 11: SEM images of the brazed gaps prepared with molybdenum acid etchant

ogy. The gap brazed according to the second cycle shows a finer $\gamma / \gamma^{\prime}$ morphology (Fig. 11 (c), (d)). In this case, the fine bright plates within the $\gamma$ matrix are also visible, however, their amount seems to be lower compared to the first cycle. In Fig. 11 (e), a very fine morphology was achieved by the solution annealing and the following precipitation hardening. Compared to the base material where a mean $\gamma^{\prime}$ diameter of about $0.7 \mu \mathrm{m}$ was measured (Fig. 10), the $\gamma^{\prime}$ precipitations in this case are finer (about $0.25 \mu \mathrm{m}$ ). Moreover, the amount of $\gamma^{\prime}$ seems to be higher than within the other gaps, however, the $\gamma^{\prime}$ precipitations 
become larger within the boundary zone of the braze gap (Fig. 11 (f)).

In order to detect the crystallographic orientation distribution within the brazed gaps, electron backscatter diffraction (EBSD) analysis was carried out. All EBSD results were visualized by orientation maps, misorientation profiles and pole figures (Figs. 12-14). For the orientation maps the inverse pole figure coloring (IPF) was used, whereby the reference direction was the sample $\mathrm{x}$-axis. The corresponding color legend is depicted in Fig. 15. The misorientation profiles were measured perpendicular to the gap, labeled by a black line. All profiles were plotted relative to the first point which was chosen in each case on the left boundary within the base material.

As pole figures the $\langle 001\rangle$ direction was plotted which means that the break-through points of the $\langle 001\rangle$ directions are projected onto the equatorial plane of a projection globe. In case of a single crystalline orientation, three discrete projection points have to be visible in the pole figure; polycrystalline materials produce statistically distributed points. In this case, the primary orientation $\langle 001\rangle$ is parallel to the $\mathrm{x}$-axis, the gap is perpendicular to this, therefore, all projection points should lie on the axes of the pole figure coordinate system. However, since the secondary orientations are not fixed, the position of the corresponding break-through points can be distributed over the whole y-z-plane; in the $\langle 001\rangle$ pole figures no exact $\mathrm{y}$-position is fixed.

The misorientation profiles show that the maximum misorientation measured relative to the first point is in the range of $5^{\circ}$ (Fig. 14 (d)). Small orientation differences are also visible in the IPF coloring within the orientation maps. Large angle grain boundaries with an orientation difference exceeding $10^{\circ}[16]$ are marked by black lines. However, no real grain boundaries are visible within the IPF maps (in Fig 12 (b), a carbide has been detected). All pole figures show three discrete projection areas. With exception of Fig. 13(c), each pole figure shows a small rotation of the projection points. Obviously, small orientation deviations of the $\langle 001\rangle$ from the sample $\mathrm{x}$-axis direction are at hand. However, for the analysis of epitaxial solidification the exact sample orientation is not essential. Altogether, it is concluded from the results of EBSD analysis that complete epitaxial solidification by use of the enhanced alloy system was successful in any brazing cycle.

\section{Discussion}

In conventional transient liquid phase bonding (TLP) technologies usually boron and/or silicon are used as

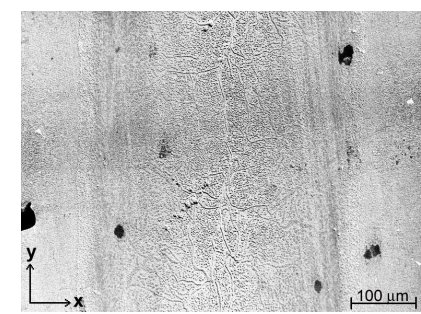

(a) SEM-image

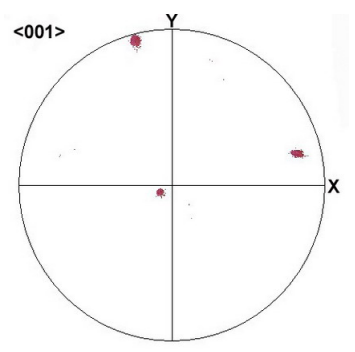

(c) $\langle 001\rangle$ pole figure

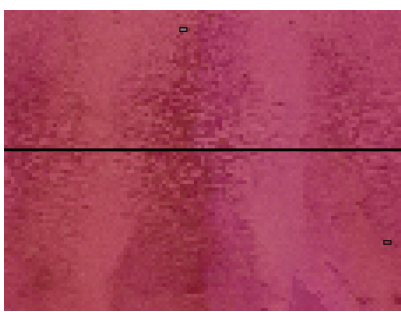

(b) orientation map, IPF coloring

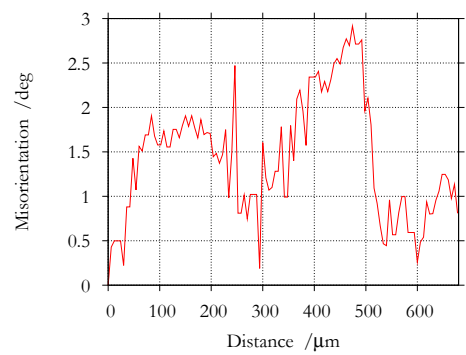

(d) misorientation profile, relative to first point
Figure 12: Cycle 1

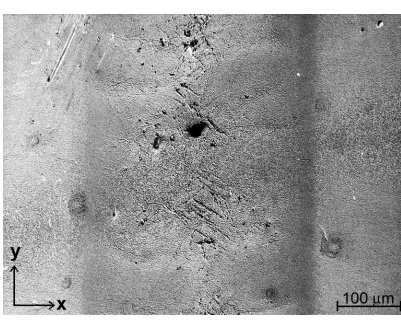

(a) SEM-image

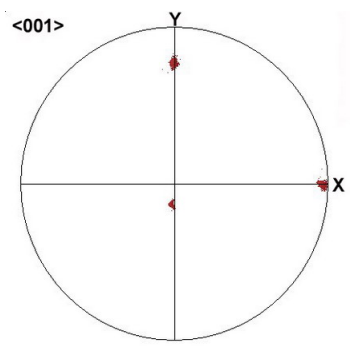

(c) $\langle 001\rangle$ pole figure

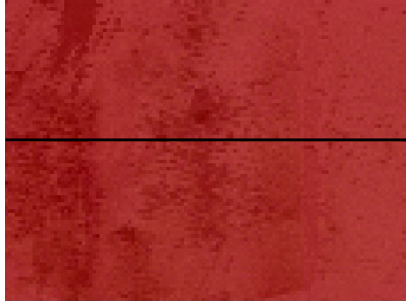

(b) orientation map, IPF coloring

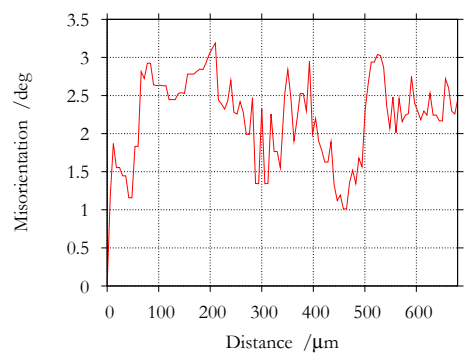

(d) misorientation profile, relative to first point

Figure 13: Cycle 2 melting point depressants $[7,16]$. Elements such as phosphorus, hafnium and zirconium are also possible to lower 


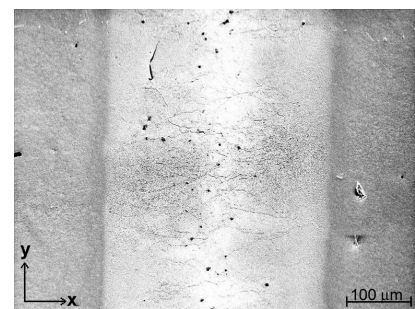

(a) SEM-image

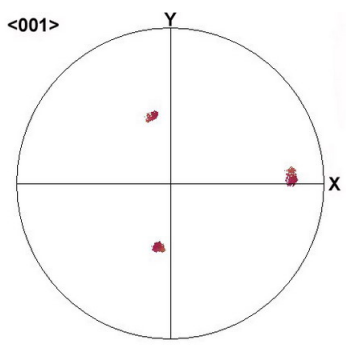

(c) $\langle 001\rangle$ pole figure

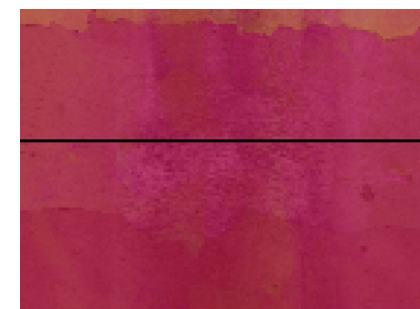

(b) orientation map, IPF coloring

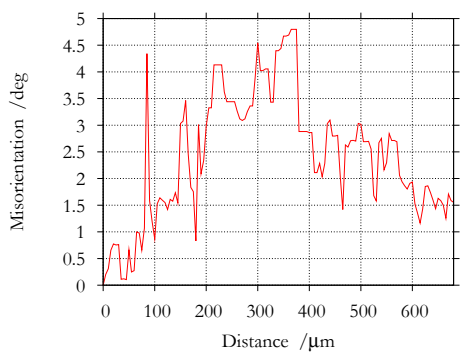

(d) misorientation profile, relative to first point

Figure 14: Cycle 3

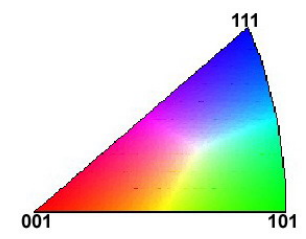

Figure 15: Inverse pole figure legend

the melting point in nickel based materials, however, the use of these elements is of lesser extent [16]. It is observed that an epitaxial bridging of braze gaps in single crystalline alloys can be achieved within long hold times in the range of several hours in combination with high temperatures. The braze microstructure in the gap is similar to that of the base material consisting of $\gamma^{\prime}$ cubes in a $\gamma$ matrix [7, 18]. Furthermore, a homogenization between filler and surrounding base material takes place. A concentration of the melting point depressant below the solubility boundary is assured.

Because of its high diffusivity in nickel, shortest brazing times are achieved with boron containing filler alloys. However, due to its poor solubility, insufficient hold times lead to brittle secondary phases, serving as nucleation sites for stray grains. In case of incomplete epitaxial growth solidification is finished by an eutectic reaction resulting in a multiphase and polycrystalline microstructure. High temperatures and long hold times cause a coarsening of the base material with the result of deteriorating mechanical properties, specially the stress rupture behavior is influenced [7, 18]. Altogether, the problem of conventional TLP is, that either the base material looses its mechanical properties or insufficient hold times involve weak polycrystalline braze gaps [7].

In [17] Ni-Mn filler systems were developed which permit solidification times being 100 times shorter than conventional TLP technologies. This gives the possibility of brazing even larger gaps in economically justifiable times. This is primarily caused by the high solubility of manganese in the solid $\gamma$ phase and the low segregation tendency to the liquid phase. In contrast to the eutectic Ni-B system the Ni-Mn system is azeotropic. In the first case, an incomplete diffusion of boron causes a solidification ending with the final eutectic reaction. In the second case, single phase solidification occurs even in case of very fast quenching, no secondary phase can precipitate. For this reason, epitaxial solidification can be accomplished within very short times without nucleation of stray grains. However, the binary and ternary Ni-Mn systems developed in [17], contain neither any $\gamma^{\prime}$ formers nor elements providing a beneficial corrosion behavior. Therefore, in order to produce a $\gamma / \gamma^{\prime}$ microstructure similar to that of the base material, in this work $\mathrm{Cr}$ and $\mathrm{Al}$ were added. The second melting point depressant was replaced by $\mathrm{Ti}$, since $\mathrm{Ti}$ increases the wettability of the braze alloy and shifts the $\gamma^{\prime}$ solution to higher temperatures.

As first step, thermodynamic simulations were conducted which revealed that the amount of $\mathrm{Al}$ has to be restricted in order to avoid the formation of $\mathrm{NiAl}$ which results in lower amounts of $\gamma^{\prime}$. With regard to Cr, it was found that the addition of $\mathrm{Cr}$ causes lower $\gamma^{\prime}$ precipitation temperatures. However, $\mathrm{Cr}$ is necessary as $\mathrm{Cr}_{2} \mathrm{O}_{3}$ former and, therefore, as corrosion protecting element. As compromise $5 \mathrm{wt} . \%$ were selected; in order to compensate the lower $\gamma^{\prime}$ precipitation temperature, $3 \mathrm{wt} . \%$ of Ti were added. As result of the simulations, an alloy consisting of Ni-25Mn-5Cr-3Al-3Ti, was chosen as system for the following brazing experiments. The subsequent kinetic simulation confirmed that the system is suitable for epitaxial solidification: No secondary phases were predicted during solidification.

Within the experiments three different brazing cycles were applied resulting in different microstructures. The first cycle which consists of a $5 \mathrm{~h}$ lasting ramp between the brazing temperature and the final temperature without any heat treatment, produced a coarse $\gamma^{\prime}$ morphology. In addition to the $\gamma$ and $\gamma^{\prime}$ phase, a third one is visible which 
precipitated as small plates parallel and perpendicular to the gap orientation. It is assumed that these fine precipitations are also part of the $\gamma^{\prime}$ phase, since it is similar to a typical bidisperse microstructure which can be observed within $\gamma^{\prime}$ hardened nickel based superalloys: After cooling below the $\gamma^{\prime}$ solvus temperature, relatively high amounts of $\gamma^{\prime}$ are formed [18]: On the one hand, coarse particles, on the other hand very fine precipitations which are called 'Cooling- $\gamma$ '. Within the microstructure which is visible in Fig. 11 (b), the coarse particles were identified as $\gamma^{\prime}$. Since the fine precipitations show a similar etching behavior, it is assumed, that they belong to the same phase.

In [18] it is described that the microstructure which is formed during cooling below the $\gamma^{\prime}$ solvus temperature, can be improved by an age hardening, typically at $1123 \mathrm{~K}$ for 16 to $24 \mathrm{~h}$. Within the second brazing cycle, an age hardening at $1153 \mathrm{~K}\left(177 \mathrm{~K}\right.$ below the $\gamma^{\prime}$ solvus temperature) for $2 \mathrm{~h}$ was attached. In case of $\gamma^{\prime}$ hardened superalloys, usually this heat treatment results in a bidisperse microstructure: The fine primary $\gamma^{\prime}$ growths, furthermore, new nuclei are formed. Small secondary $\gamma$ ' as well as coarser primary $\gamma^{\prime}$ precipitations are at hand. In Fig. 11 (d) this effect can also be observed. The number of the fine plates has decreased significantly, small round precipitations are visible which are assumed to be secondary $\gamma^{\prime}$. Due to the faster cooling, the primary $\gamma^{\prime}$ precipitations are smaller than within the gap corresponding to the first cycle. Probably, during a longer age hardening the plate-shaped precipitations would dissolute completely; only large round primary and small round secondary precipitations would remain. Within the gap brazed according to the second cycle, a further phase is visible which forms diagonal to the gap direction (Fig. 8 (a), (d), 11 (c)). Within the etched sample analyzed by means of SEM, this phase has also be dissolved, thus, for identification another preparation has to be fabricated.

In case of the third brazing cycle, a heat treatment which is typical for the superalloy CMSX-4 was attached: Solution annealing at $1353 \mathrm{~K}$ for $1 \mathrm{~h}$, followed by a precipitation hardening for $2 \mathrm{~h}$ at $1123 \mathrm{~K}$ [18]. With regard to the phase transformation temperatures measured by DSC, it is expected that the effect which is caused by this heat treatment within the braze alloy is similar to that in the base material although the hold times are very short. Indeed, the microstructure within the braze gap shows the typical morphology containing a high amount of cubic-shaped $\gamma^{\prime}$ within a $\gamma$ matrix (Fig. 11 (e)). The mean $\gamma^{\prime}$ diameter is in the range of $0.25 \mu \mathrm{m}$ and, therefore, smaller than in the base material. Since too fine $\gamma^{\prime}$ precipitations usually cause a low creep strength [18], a coarser $\gamma / \gamma^{\prime}$ microstructure has to be adjusted. This can be achieved by higher temperatures during precipitation hardening [20]: Due to the faster diffusion at higher temperatures, a faster growth of the $\gamma^{\prime}$ nuclei is provided.

The second and the third brazing cycle induced dendritic solidification because the cooling rate was increased compared to the first cycle (Figs. 8 (a), 9 (a)). It is concluded that a change from planar to dendritic solidification front took place, as it occurs during single crystalline fabrication (Bridgman process) during sufficiently high supercooling [18, 21]. In case of a dendritic structure, a complete solution annealing is difficult: Because of concentration differences between the dendrite arms and the interdendritic regions, varying amounts of $\gamma^{\prime}$ precipitate. The Ti-concentration within the dendrites is lower than in-between, a lower $\gamma^{\prime}$ fraction is precipitated which results in a lower $\gamma^{\prime}$ solvus temperature. At the same time, the solidus temperature within the interdendritic regions is lower, due to the higher amount of Ti. Therefore, a full solution annealing is not possible, since incipient melting within the interdendritic regions occurs [18]. With regard to the third cycle, the differences of the $\gamma / \gamma^{\prime}$ microstructure within the dendrites and the interdendritic regions still has to analyzed more accurately. However, since no primary $\gamma^{\prime}$ is visible within the gap, it is concluded that the solution annealing at $1353 \mathrm{~K}$ caused a complete $\gamma^{\prime}$ solution. The concentration differences seem to be relatively small, hence, the dendritic and interdendritic $\gamma^{\prime}$ solvus temperature and the liquidus temperature do not differ very much.

In addition to the precipitation morphology discussed above, in all three cycles, some $\gamma^{\prime}$ precipitations form long cord-shaped precipitations. Although this is less pronounced for the third cycle, their formation still has to be examined and, where applicable, avoided by further heat treatments.

All three cycles produced an epitaxially solidified braze gap. The aim to produce a microstructure similar to that of the base material, has almost been achieved. Further mechanical experiments will be conducted in near future to examine the high temperature stability of the brazed gaps. However, obviously the epitaxial solidification by use of Ni-Mn based systems seems to be relatively stable. The enhancement by $\mathrm{Cr}$ and $\mathrm{Al}$ did not influence the epitaxial growth, therefore, it is expected, that the change of the composition or the addition of further elements, if necessary, will not be a problem with regard to the developed brazing technology. 


\section{Conclusions}

The epitaxial high temperature brazing of $300 \mu \mathrm{m}$ wide gaps within very short brazing times, using an $\mathrm{Ni}-\mathrm{Mn}$ based alloy system which was enhanced by $\mathrm{Cr}, \mathrm{Al}$ and $\mathrm{Ti}$, was demonstrated. The following conclusions can be drawn:

1. The Ni-Mn based braze alloys which were identified as suitable systems for the fast epitaxial high temperature brazing of single crystalline nickel based superalloys [17], were enhanced by $\mathrm{Cr}$ and $\mathrm{Al} ; \mathrm{Si}$ as second melting point depressant was replaced by Ti. In order to provide an appropriate high temperature stability and a beneficial corrosion behavior, $\mathrm{Cr}$ and $\mathrm{Al}$ were added as $\gamma$ solution hardeners, oxide film formers $\left(\mathrm{Al}_{2} \mathrm{O}_{3}, \mathrm{Cr}_{2} \mathrm{O}_{3}\right)$ as well as $\gamma^{\prime}$ formers (Al). Ti was used to provide a good wettability combined with a $\gamma^{\prime}$ stabilizing effect.

2. By use of the enhanced system Ni-25Mn-5Cr-3Al3Ti (in wt.-\%) a complete epitaxial solidification was achieved by various brazing cycles. The process is robust towards changes in temperatures control.

3. The solidification of the enhanced system is also not diffusion controlled, hence, fast cooling is possible, the necessary brazing are not longer than in case of the binary ans ternary Ni-Mn based systems.

4. A solution annealing followed by a precipitation hardening subsequent to the brazing cycle produced a microstructure similar to that of the base material: A high amount of cubic $\gamma^{\prime}$ within the $\gamma$ matrix.

\section{References}

[1] K. C. Antony and G. W. Goward. 6. Int. Symp. on Superalloys, pages 745-754, 1988.

[2] P. Brauny, M. Hammerschmidt, and M. Malik. Mater. Sci. and Tech., 1:719-727, 1985.

[3] S. Humm. Untersuchungen zur Entwicklung eines Reparaturverfahrens für einkristalline und gerichtet erstarrte Turbinenkomponenten aus Nickelbasissuperlegierungen. RWTH Aachen, 2003.

[4] O. A. Idowu, N. L. Richards, and M. C. Chaturvedi. Mat. Sci. and Eng., A 397(1-2):98-112, 2005.

[5] O. A. Idowu, O. A. Ojo, and M. C. Chaturvedi. Metall. and Mater. Trans., 37 A(9):2787-2796, 2006.
[6] W. Li, T. Jin, X. Sun, Y. Guo, and H. Guan. J. of Mater. Sci. and Tech., 18(1):54-56, 2002.

[7] B. Hoppe. Verhalten gelöteter NickelbasisSuperlegierungen unter thermischer Ermüdungsbelastung. TU Braunschweig, 2003.

[8] D. S. Duvall, W. A. Owczarski, and D. F. Paulonis. Weld. J., 53(4):203-214, 1974.

[9] K. A. Ellison, P. Lowden, and J. Liburdi. J. of Eng. for Gas Turbines and Power, 116:237-242, 1994.

[10] L. S. K. Heikinheimo, A. Laukkanen, and J. Veivo. Weld. in the World, 49(5/6):5-12, 2005.

[11] B. Heine. Zeitschrift für Metallkunde, 49(6):393-400, 1995.

[12] J.-P. Jung, B.-Y. Lee, and C.-S. Kang. Int. Trends in Weld. Sci. and Tech.: Proceed. of an Int. Conf., pages 1101-1105, 1993.

[13] D. U. Kim. J. of the Korean Inst. of Metals and Materials, 39(5):589-594, 2001.

[14] K. Nishimoto, K. Saida, D. Kim, and Y. Nakao. Weld. in the World, 41(2):121-131, 1998.

[15] J. E. Ramirez and S. Liu. Weld. J., 71(10):365-375, 1992.

[16] A. Schnell. A study of the Diffusion Brazing Process applied to the single crystal superalloy CMSX-4. EPF de Lausanne, 2004.

[17] B. Laux, S. Piegert, and J. Rösler. Fast epitaxial high temperature brazing of single crystalline nickel based superalloys, submitted to Metall. and Mater. Trans., 2007.

[18] R. Bürgel. Handbuch HochtemperaturWerkstofftechnik. Vieweg \& Sohn Verlagsges. mbH, Braunschweig, Wiesbaden, 2001.

[19] P. Villars. Pearson's Handbook. ASM International, Materials Park, OH 44073, 1997.

[20] J. F. Shackelford. Materials Science for Engineers. Pearson Education, Inc., Upper Saddle River, New Jersey, 2005.

[21] P. R. Sahm, I. Egry, and T. Volkmann. Schmelze, Erstarrung, Grenzflächen. Vieweg \& Sohn Verlagsgesellschaft mbH, Braunschweig, Wiesbaden, 1999. 